Relevance and formation mechanisms of negative ions upon ablation of $\mathrm{Al}_{2} \mathrm{O}_{3}$

This article has been downloaded from IOPscience. Please scroll down to see the full text article.

2012 J. Phys. D: Appl. Phys. 45285402

(http://iopscience.iop.org/0022-3727/45/28/285402)

View the table of contents for this issue, or go to the journal homepage for more

Download details:

IP Address: 161.111.22.141

The article was downloaded on 04/04/2013 at 10:41

Please note that terms and conditions apply. 


\title{
Relevance and formation mechanisms of negative ions upon ablation of $\mathrm{Al}_{2} \mathrm{O}_{3}$
}

\author{
R J Peláez ${ }^{1}$, C N Afonso ${ }^{1}$, J Chen ${ }^{2}$, M Esposito², Th Lippert ${ }^{2}$, D Stender ${ }^{2}$ \\ and A Wokaun ${ }^{2}$ \\ ${ }^{1}$ Laser Processing Group, Instituto de Optica, CSIC, Serrano 121, Madrid 28006, Spain \\ ${ }^{2}$ Paul Scherrer Institut, General Energy Research Department, CH-5232 Villigen PSI, Switzerland
}

Received 20 March 2012, in final form 31 May 2012

Published 28 June 2012

Online at stacks.iop.org/JPhysD/45/285402

\begin{abstract}
The aim of this work is to study the significance of negative ions in the plasma produced by ablation of a simple oxide ceramic target $\left(\mathrm{Al}_{2} \mathrm{O}_{3}\right)$ at distances and fluences typically used in pulsed-laser deposition processes. The results show that negative ions are indeed produced, the majority of which $(>82 \%)$ being $\mathrm{O}^{-}$that are predominantly produced by neutralization of $\mathrm{O}^{+}$ followed by electron attachment. They represent one third of the $\mathrm{O}^{+}$population at low fluences for a distance of $4 \mathrm{~cm}$ from the target at which most deposition experiments are performed. $\mathrm{AlO}^{-}$represents up to $15 \%$ of the negative ions and their amount increases at the expense of $\mathrm{O}^{-}$as fluence is increased. The most abundant as well as the fastest species in the plasma is by far $\mathrm{Al}^{+}$that represent $>80 \%$ of ions having kinetic energy $<100 \mathrm{eV}$ at low fluences. This result is consistent with earlier discussion on the possible existence of direct photoionization processes due to the high $(6.4 \mathrm{eV})$ photon energy. Saturation effects, the formation mechanism for $\mathrm{AlO}^{-}$and $\mathrm{Al}^{2+}$, and expansion dynamics for negative ions are finally discussed.
\end{abstract}

\section{Introduction}

Pulsed-laser deposition (PLD) is nowadays acknowledged as an excellent technique for the production of nanostructures and complex oxides. The nucleation and growth processes as well as the final properties of the films depend very much on the nature and kinetic energies (KEs) of the species arriving to the substrate. In PLD, ions are generally the more energetic species and are responsible for high mobility, sputtering and implantation effects at substrate level. However, only positive ions are usually referred to as ions despite the fact that it is well known that negative ion bombardment is responsible for re-sputtering and damage at the substrate in magnetron sputtering processes [1-3], enhancing the formation of metastable structures [4], or producing etching rates similar to positive ions $[5,6]$. It has been shown that negative ions produced upon RF magnetron sputtering of $\mathrm{MgO}$ have KEs ranging up to values higher than $500 \mathrm{eV}$ [7]. In spite of the several similarities between sputtering and PLD processes, the existence of negative ions in the ablation process has been scarcely reported and thus their influence in film growth is practically unknown.

The existence and importance of negative ions in the ablation process was reported in the 1990s and practically ignored since then. Early studies on ablation of $\mathrm{YBaCuO}$ targets reported the thermal emission of $\mathrm{O}^{-}(1 \mathrm{eV})$ [8] and a comparable flux of positive and negative ions [9], the energy distribution of the latter overlapping with the high-energy part of the former. Negatively charged oxide species were detected upon ablation of AIN containing oxygen impurities and it was concluded that a bias was needed to obtain stoichiometric films in order to accelerate positive ions and reject the negative oxide ions [10]. Similarly, it was found that negatively charged species were oxygen rich upon ablation of lead titanate and lead and titanium oxide and the high-mass species are thus good oxygen carriers [11].

More recently, an improvement of film quality has been reported when ablating $\mathrm{La}_{0.6} \mathrm{Ca}_{0.4} \mathrm{MnO}_{3}$ in the presence of $\mathrm{N}_{2} \mathrm{O}$ gas that coincides with the largest amount of negatively charged oxygen species $[12,13]$. However, these works show on the one hand that the amount of negatively charged species is less important and almost non-relevant in $\mathrm{O}_{2}$ and vacuum, respectively. On the other hand, their fluence dependence, origin or expansion is not discussed. Interestingly, in spite of the high electron affinities of halogens [14], studies of ablation of alkali halides at power densities below the threshold for optical breakdown and plume formation show no evidence for negative halogen ions [15]. In addition, it is shown that 
positive and negative alkali ions show a high degree of spatial and temporal overlap similarly to what was reported earlier for $\mathrm{YBaCuO}$ [9].

The aim of this work is to study the significance of negative ions in the PLD process of oxides and if they are associated with a gas background as suggested earlier $[12,13]$. Important aspects included in this work are the relevance of negative ions with respect to positive ions and neutrals, if their KEs are comparable to positive ions, their formation mechanism and how they expand and eventually reach the substrate. For this study, we have selected an oxide ceramic target $\left(\mathrm{Al}_{2} \mathrm{O}_{3}\right)$, i.e. a simple binary oxide formed by a low-mass metal as opposed to earlier studies that involved complex oxides $[8,9,12,13]$. On the one hand, transparent and high refractive index films and waveguides could be obtained by PLD of ceramic $\mathrm{Al}_{2} \mathrm{O}_{3}$ in vacuum $[16,17]$ and thus, any possible contribution of gas species in producing negative ions $[12,13]$ can be ruled out. On the other hand, it has been reported that positive aluminium ions dominate the plasma produced by ablation of $\mathrm{Al}_{2} \mathrm{O}_{3}$ at $193 \mathrm{~nm}$ and have KEs up to $1 \mathrm{keV}$ [18]. They were found responsible for important sputtering effects at substrate level during the production of a- $\mathrm{Al}_{2} \mathrm{O}_{3}$ films nanostructured with metal nanoparticles that lead to a self-regulation of the growth process [19]. Moreover, several negative oxide species with significant KEs have recently been identified in the production of $\mathrm{Al}_{2} \mathrm{O}_{3}$ films by dc pulsed-magnetron discharge [20].

\section{Experimental}

Experiments have been performed in a vacuum chamber with a residual pressure of $10^{-7}$ mbar. We have used an ArF excimer laser $(\lambda=193 \mathrm{~nm}, \tau=20 \mathrm{~ns})$ operated at $5 \mathrm{~Hz}$ and focused at $45^{\circ}$ on a cylindrical ceramic $\mathrm{Al}_{2} \mathrm{O}_{3}$ target. A rectangular aperture was used to image the beam at the target to a spot size of $\approx 0.63 \mathrm{~mm}^{2}$ as opposed to the earlier work studying the positive ions upon ablation of ceramic $\mathrm{Al}_{2} \mathrm{O}_{3}$ in which the beam was focused [18]. It is worth pointing out that direct comparison of absolute fluences used in this work and those reported earlier is not straightforward due to the different energy profiles at the target and furthermore, the fact that the ionic content of the plasma is expected to be higher under the present conditions [21]. The laser fluence was varied in this work in the range $0.4-2.4 \mathrm{~J} \mathrm{~cm}^{-2}$.

The species produced by ablation were analysed by a quadrupole mass spectrometer (EQP Hiden) with a mass ranging from 1 to $500 \mathrm{amu}$ and triggered by the signal from a photodiode detecting the laser light. The KE of the species was measured using an electrostatic energy analyser located along the direction perpendicular to the target with a KE range up to $100 \mathrm{eV}$. The collection yield depends on the acquisition gating conditions that are optimum for ion detection using a delay time of $20 \mu \mathrm{s}$ and an acquisition time of $400 \mu \mathrm{s}$. The species go first into an ionizer stage through a nozzle and the whole spectrometer system can be displaced in the axial direction. For this work, we have selected a nozzle with diameter of $0.6 \mathrm{~mm}$ and $4 \mathrm{~cm}, 6 \mathrm{~cm}$ and $8 \mathrm{~cm}$ as the distance $Z$ between the target surface and the nozzle. For the charged species analysis, the ionizer is switched off and the species become deflected

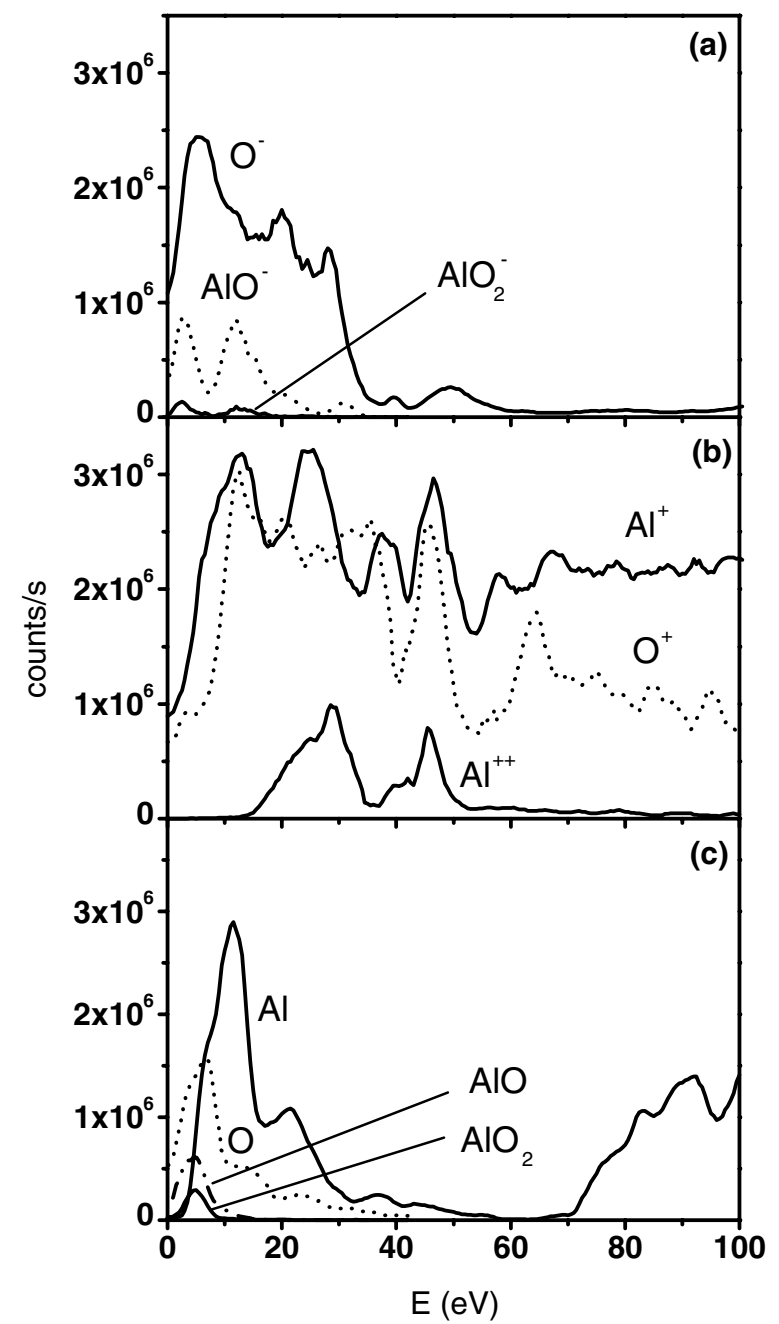

Figure 1. KE distributions at $\boldsymbol{Z}=4 \mathrm{~cm}$ of relevant ( $a$ ) negative ions, (b) positive ions and $(c)$ neutrals upon ablation with a fluence of $2.0 \mathrm{~J} \mathrm{~cm}^{-2}$.

according to their mass to charge ratio and thus the detection efficiency for positive and negative charged ions is the same. For the neutral species analysis, the ionizer is switched on and the amount of ionized species that are finally collected by the detector is thus affected by their ionization cross section. A field was applied to the EQP extractor to reject all incoming charged species. A quantitative comparison between the amount of charged and neutral species and among different neutral species is therefore not straightforward. Further details of the experimental set-up can be found elsewhere [12].

\section{Results and discussion}

Figure 1 shows the KE distributions (N(KE)) of relevant $(a)$ negative ions, $(b)$ positive ions and $(c)$ neutrals for a fluence of $2.0 \mathrm{~J} \mathrm{~cm}^{-2}$. It is seen that a number of species are relevant for $\mathrm{KE}<60 \mathrm{eV}$, while only $\mathrm{Al}^{+}, \mathrm{O}^{+}$, and to a lesser extent $\mathrm{Al}$, are relevant in the whole studied energy range (up to $100 \mathrm{eV}$ ). For $\mathrm{KE}<60 \mathrm{eV}$ and in order of decreasing intensity, the relevant species are (i) $\mathrm{O}^{-}$and $\mathrm{AlO}^{-}$for negative ions, with minor traces of $\mathrm{AlO}_{2}^{-}$; (ii) $\mathrm{O}^{+}, \mathrm{Al}^{+}$, and to a lesser extent $\mathrm{Al}^{2+}$, for positive ions; (iii) $\mathrm{Al}$ and $\mathrm{O}$ for neutral species, with minor 


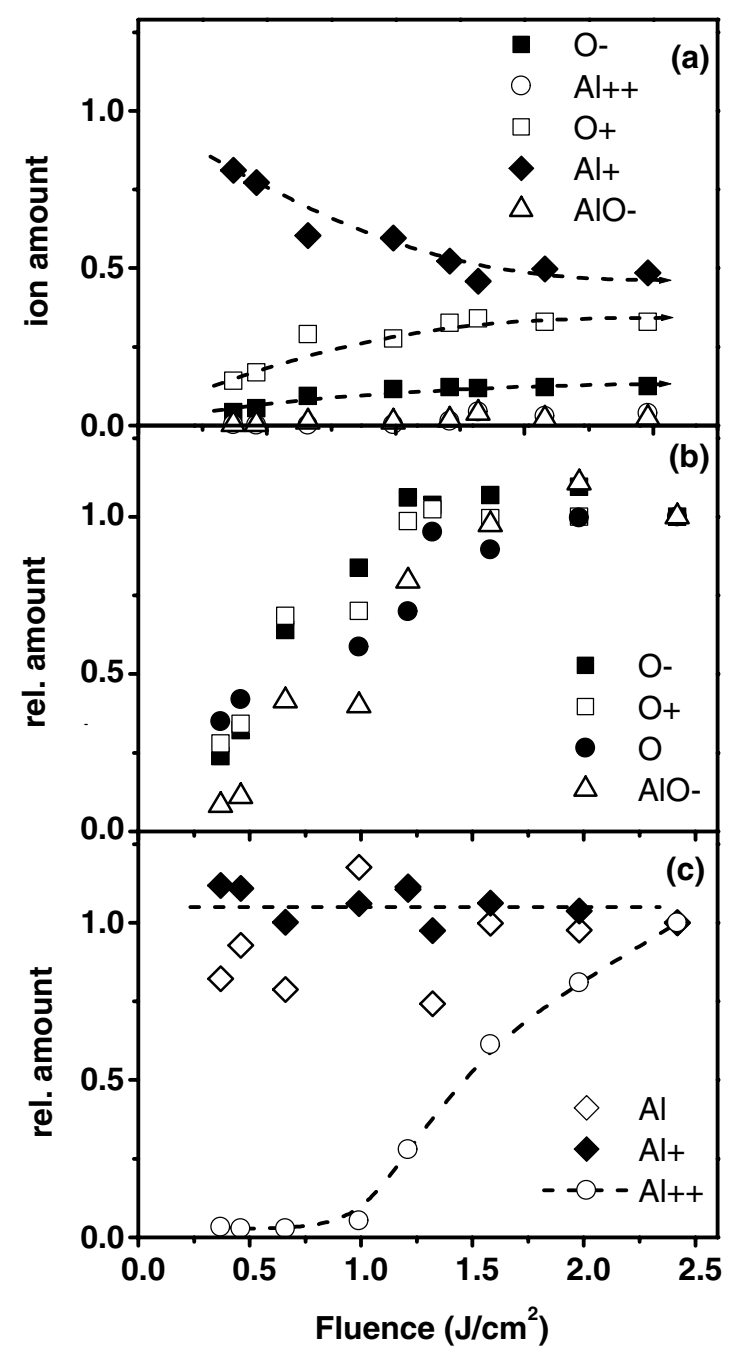

Figure 2. Relative amount of $(a)$ ionic species, $(b)$ oxygen/oxide species and (c) aluminium species at $Z=4 \mathrm{~cm}$ as a function of fluence for $(\mathbf{\square}) \mathrm{O}^{-},(\bullet) \mathrm{O},(\square) \mathrm{O}^{+},(\diamond) \mathrm{Al},(\diamond) \mathrm{Al}^{+},(\mathrm{O}) \mathrm{Al}^{2+}$ and $(\triangle)$ $\mathrm{AlO}^{-}$. The normalization factors are (a) the total amount of ions and (b),(c) the value at the highest fluence studied in each case. Dashed lines are the guidelines.

traces of $\mathrm{AlO}$ and $\mathrm{AlO}_{2}$. Overall, the most abundant ions are $\mathrm{Al}^{+}$and $\mathrm{O}^{+}$(figure $1(b)$ ) and irrespective of the fluence, the former has an almost constant $\mathrm{N}(\mathrm{KE})$ in the studied range and the $\mathrm{N}(\mathrm{KE})$ of the latter decreases for $\mathrm{KE}>65 \mathrm{eV}$. The most abundant negative ion is $\mathrm{O}^{-}$and its amount with respect to the total negative ion content decreases as fluence increases (93-82\%). Instead, both $\mathrm{AlO}^{-}$and $\mathrm{AlO}_{2}^{-}$increase as fluence increases, the former in the range $6-15 \%$ while the latter remains below $1.5 \%$. Some species show a dominant two $\left(\mathrm{AlO}^{-}\right.$and $\left.\mathrm{Al}^{2+}\right)$ or more $\left(\mathrm{O}^{+}, \mathrm{O}^{-}, \mathrm{Al}\right)$ peak structures that behave differently as a function of fluence. Whereas the two peaks increase smoothly with fluence for the case of $\mathrm{Al}^{2+}$, the dominant highest energy one appears for fluences higher than $0.7-1.0 \mathrm{~J} \mathrm{~cm}^{-2}$ for the cases of $\mathrm{AlO}^{-}$and $\mathrm{Al}$.

The amount of certain species is calculated by integrating its KE distribution (as those plotted in figure 1) for each fluence. Figure 2(a) shows the amount of several ions to the total amount of ions ratio measured in this work. It is seen that $\mathrm{Al}^{+}$, $\mathrm{O}^{+}$and $\mathrm{O}^{-}$represent $\approx 92 \%$ of ions and all tend to saturate for fluences $>1.2 \mathrm{~J} \mathrm{~cm}^{-2}$ for which the proportion of $\mathrm{Al}^{+}: \mathrm{O}^{+}: \mathrm{O}^{-}$ is $48: 32: 12$, while for low fluences $\mathrm{Al}^{+}$represent $>80 \%$ of the ions. However, the $\mathrm{Al}^{+}$amount (with $\mathrm{KE}<100 \mathrm{eV}$ ) is $<26 \%$ of the total amount of $\mathrm{Al}^{+}$as calculated from the extrapolation to zero of the data reported in figure 4(a) of [18] for the $\mathrm{N}(\mathrm{KE})$ of $\mathrm{Al}^{+}$produced at $2.5 \mathrm{~J} \mathrm{~cm}^{-2}$ [18]. Furthermore, the $\mathrm{N}(\mathrm{KE})$ distribution in figure $1(b)$ for $\mathrm{O}^{+}$has a complex structure and in spite of the noise, the following parts could clearly be identified for increasing KEs: a broad band at low KEs, a narrow band in the range $40-54 \mathrm{eV}$ and a broad band with the maximum around $65 \mathrm{eV}$ followed by a long decay. The proportion of $\mathrm{O}^{+}$in this latter band is at the most $54 \%$ of the total amount of $\mathrm{O}^{+}$detected and it becomes $<30 \%$ for the highest fluence studied, i.e. the proportion of energetic $\mathrm{O}^{+}$ ions within the studied interval decreases as fluence increases. These results are consistent with the earlier conclusion that the ionic component of the plasma produced by ablation of $\mathrm{Al}_{2} \mathrm{O}_{3}$ at $193 \mathrm{~nm}$ is dominated by $\mathrm{Al}^{+}$and discussed in terms of direct photoionization processes due to the energy of the laser $(6.4 \mathrm{eV})$ being higher than the ionization potential of $\mathrm{Al}$ $(5.98 \mathrm{eV})$ [18].

Negative ions can be formed from neutrals in several physical processes such as radiation capture, electronic recombination, dissociative attachment and ternary collisions. However, only the last one was found relevant for the case of laser ablation because the first two processes have low probability and the dissociative attachment was not likely because the molecular neutrals have very low KE compared with ions [9] and the same happens in our case since their $\mathrm{KE}$ are $<10 \mathrm{eV}$, as seen in figure $1(c)$. The most likely mechanism suggested elsewhere [9] is then ternary collisions $\left(\mathrm{O}+\mathrm{e}^{-}+\mathrm{e}^{-} \rightarrow \mathrm{O}^{-}+\mathrm{e}^{-}\right.$or $\mathrm{O}+\mathrm{O}+\mathrm{e}^{-} \rightarrow \mathrm{O}^{-}+\mathrm{O}$. Although in our case there is an overlapping at around $5 \mathrm{eV}$ of the $\mathrm{N}(\mathrm{KE})$ of $\mathrm{O}^{-}$and that of $\mathrm{O}$, that of the latter decreases sharply for higher KEs and other processes have to be thus considered to explain the broad band observed in the $\mathrm{N}(\mathrm{KE})$ of $\mathrm{O}^{-}$. An overlap between the $\mathrm{N}(\mathrm{KE})$ of negative ions and of the corresponding positive ions has been reported earlier, especially on the highest KE side $[9,15]$. Our results show apparently an opposite behaviour since most $\mathrm{O}^{-}(>90 \%)$ have $\mathrm{KE}<34 \mathrm{eV}$ whereas $\mathrm{O}^{+} \mathrm{KEs}$ expand over the whole studied range irrespective of the fluence. The similarity between the major broad band of $\mathrm{O}^{-}$and the broad band at low $\mathrm{KE}$ range of the corresponding positive $\mathrm{O}^{+}$suggests that neutralization of positive ions via radiative capture or collisional recombination with electrons followed by the attachment of electrons to the neutral $[9,15]$ is the most likely process in our case. If we take into account that this broad band develops from the narrow band peaking at $5 \mathrm{eV}$, production of $\mathrm{O}^{-}$from $\mathrm{O}^{+}$becomes the predominant process.

The $\mathrm{N}(\mathrm{KE})$ of $\mathrm{AlO}^{-}$(figure $1(a)$ ) has two clear populations: a slow one centred at $\approx 3 \mathrm{eV}$ and a faster one centred at $\approx 12 \mathrm{eV}$, the latter becoming important for fluences $>0.7 \mathrm{~J} \mathrm{~cm}^{-2}$. There is an overlapping between the slow population and the $\mathrm{AlO}$ population thus suggesting the former has been generated by the attachment of electrons to the neutral diatomic species. In contrast, the position of the faster component matches very well with the intense peak observed at 
low $\mathrm{KE}$ of $\mathrm{Al}$ (figure $1(c)$ ) thus suggesting that the overlapping between the populations of $\mathrm{Al}$ and oxygen species promotes formation of $\mathrm{AlO}$ through multiple body recombinations.

Figure 2 also shows the evolution of the relative amount of $(b)$ oxygen- and $(c)$ aluminium-related species as a function of fluence obtained by normalizing their amount by the value achieved for the highest studied fluence. The results show that the relative amount of oxygen and oxide species increase with fluence from a threshold value $<0.4 \mathrm{~J} \mathrm{~cm}^{-2}$ and saturates for fluences higher than $\approx 1.2 \mathrm{~J} \mathrm{~cm}^{-2}$. Instead, the $\mathrm{Al}$ species show an almost constant value with the exception of $\mathrm{Al}^{2+}$ that shows a distinct behaviour: it increases almost linearly from a higher threshold $\left(>1 \mathrm{~J} \mathrm{~cm}^{-2}\right)$ and there is no indication of saturation. Figures $1(b)$ and 2(c) show the presence of fast $\mathrm{Al}^{+}$, even at low fluences. It is known from previous work that these ions are the fastest ions in the plasma produced by ablation of $\mathrm{Al}_{2} \mathrm{O}_{3}$ with laser photons of $193 \mathrm{~nm}$ [18]. Moreover, the N(KE) of Al figure 1 $(c)$ shows in addition to the low KE part discussed above, an increasing band for $\mathrm{KE}>70 \mathrm{eV}$ that appears for fluences $\geqslant 0.7 \mathrm{~J} \mathrm{~cm}^{-2}$ and evidencing the existence of neutrals with $\mathrm{KE}>100 \mathrm{eV}$. These high KEs suggest that these species must also be linked to the fast $\mathrm{Al}^{+}$and thus, they both travel at the front and because the ionization potential of $\mathrm{Al}$ is smaller than the photon energy, these species absorb efficiently the laser energy. Therefore, the slower species such as negative ions become shielded and increasing fluence has no significant effect on them. Similarly, if it is assumed that $\mathrm{Al}^{2+}$ is produced by ionization of $\mathrm{Al}^{+}, \mathrm{Al}^{2+}$ is not shielded and thus its amount must increase with fluence as shown in figure $2(c)$. These results are consistent with those reported elsewhere for ablation of $\mathrm{Al}$ targets at lower photon energies (355 and $532 \mathrm{~nm}$ ). For these photon energies, single photon photoionization is not feasible and photoionization can only occur through multiphoton processes at higher fluences consistently with the reported higher threshold for both saturation effects and detecting $\mathrm{Al}^{2+}[22]$.

Figure 3(a) shows the amount of $\mathrm{O}^{-}$to $\mathrm{O}^{+}$ratio as a function of the axial distance, $Z$, for the two low fluences for which the $\mathrm{KE}$ distribution of $\mathrm{O}^{+}$shows no significant amount of ions with $\mathrm{KE}$ around $100 \mathrm{eV}$ and thus quantification is reliable. It is clearly seen that this ratio decreases as the distance increases and $\mathrm{O}^{-}$are $\approx 1 / 3$ of $\mathrm{O}^{+}$at low fluences for the shortest studied distance $Z=4 \mathrm{~cm}$ that is a distance typically used to grow films by PLD. This proportion thus represents the highest proportion of $\mathrm{O}^{-}$under our experimental conditions since there are $\mathrm{O}^{+}$with $\mathrm{KE}>100 \mathrm{eV}$ for high fluences (figure $1(b)$ ) while $\mathrm{KEs}^{-}$of $\mathrm{O}^{-}$remain always below $\approx 60 \mathrm{eV}$. The constant value of this proportion supports further the link between these two populations discussed above.

Figure 3(b) shows the relative amount of the two relevant negative species, namely $\mathrm{O}^{-}$and $\mathrm{AlO}^{-}$, as a function of $Z$ where both are seen to decrease significantly as the distance is increased. Assuming an adiabatic expansion of the plasma and that the expansion dynamics is non-thermal as a result of the interaction of the laser beam with the ablated species, the amount of material arriving to a distance $r$ to the substrate is $\alpha r^{-p}$, where $p$ is the expansion coefficient ( $p=1.85$ for a spot size of $1 \mathrm{~mm}$ ) [23]. The theoretical line in

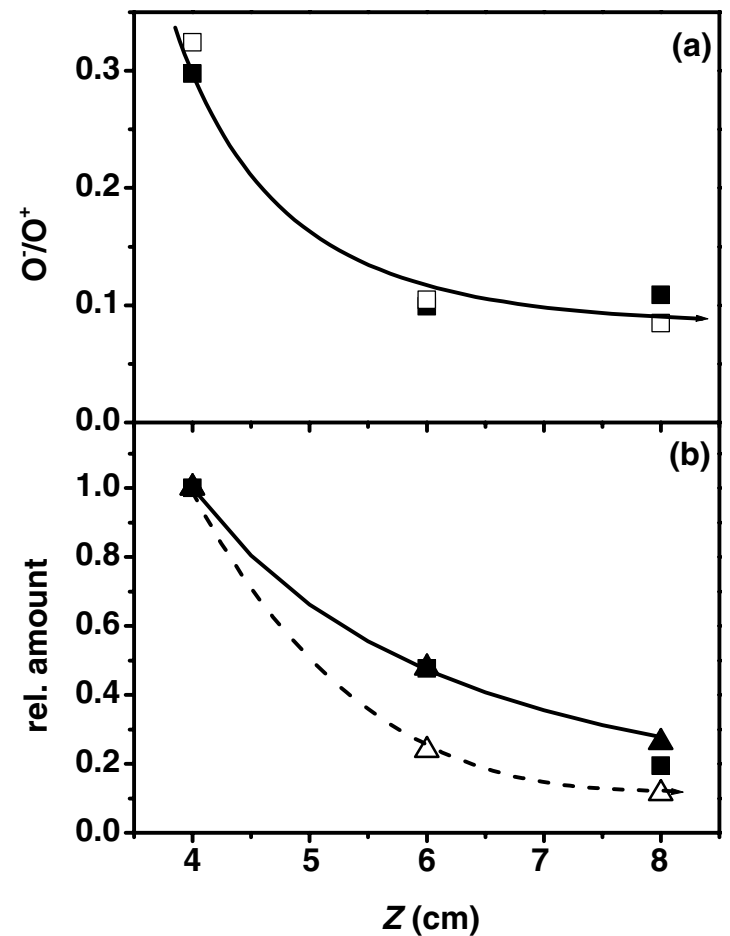

Figure 3. Several magnitudes as a function of $Z$ : $(a) \mathrm{O}^{-}$to $\mathrm{O}^{+}$ratio for ( $\mathbf{\square}) 0.4 \mathrm{~J} \mathrm{~cm}^{-2}$ and (口) $0.7 \mathrm{~J} \mathrm{~cm}^{-2}$; (b) relative amount of $(\mathbf{\square}) \mathrm{O}^{-}$, $(\triangle) \mathrm{AlO}^{-}$(all energies), $(\boldsymbol{\Lambda}) \mathrm{AlO}^{-}$(band centred at $\approx 3 \mathrm{eV}$ ) and (full line) adiabatic model for a fluence of $2.0 \mathrm{~J} \mathrm{~cm}^{-2}$. Dashed lines are the guidelines.

figure $3(b)$ has been obtained assuming this dependence and it fits very well to the experimental data for $\mathrm{O}^{-}$but differs significantly for the case of $\mathrm{AlO}^{-}$. Figure $1(a)$ shows that the $\mathrm{KE}$ distribution of $\mathrm{AlO}^{-}$for this fluence is formed by two populations centred, respectively, at $\approx 12 \mathrm{eV}$ and $\approx 3 \mathrm{eV}$ and these populations have a different behaviour with fluence and distance. While the latter population appears for all fluences and decreases smoothly as the distance increases, the former becomes negligible for $Z>4 \mathrm{~cm}$ irrespective of the fluence. The relative amount, taking only the slow population into account, is also shown in figure $3(b)$, which shows that it also expands adiabatically. This result is consistent with the different origin of the two populations of $\mathrm{AlO}^{-}$discussed above.

\section{Conclusions}

Negative ions are indeed produced by laser ablation of $\mathrm{Al}_{2} \mathrm{O}_{3}$, the majority of which $(>82 \%)$ are $\mathrm{O}^{-}$. They represent one third of the $\mathrm{O}^{+}$population for a distance of $4 \mathrm{~cm}$ from the target (at low fluences) and are predominantly produced by neutralization of $\mathrm{O}^{+}$followed by electron attachment. $\mathrm{AlO}^{-}$ represents up to $15 \%$ of the negative ions and their amount increases at the expense of $\mathrm{O}^{-}$as the fluence is increased. While the slow $\mathrm{AlO}^{-}$species are produced by attachment of electrons to the neutral species, the fast ones appear to be linked to slow neutral Al. The most abundant as well as the fastest species in the plasma is by far $\mathrm{Al}^{+}$that is consistent with the discussion earlier reported on the possible existence 
of direct photoionization processes due to the high $(6.4 \mathrm{eV})$ photon energy. The saturation effect that appears in all oxygen species as the fluence is increased is most likely related to the shielding of these slower species by the faster $\mathrm{Al}^{+}$and $\mathrm{Al}$ ones. Instead, the lack of saturation in $\mathrm{Al}^{2+}$ is consistent with their formation at the front of the plasma through collisions of $\mathrm{Al}^{+}$. Negative species produced by ternary collisions from the corresponding neutral or ionized species follow an adiabatic expansion.

\section{Acknowledgments}

This work has been partially supported by the project IZK0Z2 of the Swiss National Science Foundation. RP acknowledges a grant from the JAE-doc program, co-funded by European Social Fund.

\section{References}

[1] Dodd R, You S and Bradley J W 2010 Thin Solid Films 519 1705; and references there in

[2] Tominga K, Chong M and Shintani Y 1994 J. Vac. Sci. Technol. A 121435

[3] Rack P D, Potter M D, Woodard A and Kurinec S 1999 J. Vac. Sci. Technol. A 172805

[4] Ishikawa J 2000 Rev. Sci. Instrum. 711036

[5] Draghicia M and Stamate E 2010 J. Appl. Phys. 107123304
[6] Stamate E and Draghici M 2012 J. Appl. Phys. 111083303

[7] Toyoda H, Goto K, Ishijima T, Morita T, Ohshima N and Kinoshita K 2009 Appl. Phys. Express 2126001

[8] Wiedeman L and Helvajian H 1991 J. Appl. Phys. 704513

[9] Alimpiev S S, Belov M E, Mlinsky V V, Nikiforov S M and Romanjuk V I 1994 Appl. Phys. A 5867

[10] Chu C, Ong P P, Chen H F and Teo H H 1999 Appl. Surf. Sci. 13791

[11] Chaoui N, Millon E and Muller J F 1998 Chem. Mater. 103888

[12] Canulescu S, Lippert T and Wokaun A 2008 Appl. Phys. A 93771

[13] Esposito M, Bator M, Döbeli M, Lippert T, Schneirder C W and Wokaun A 2011 Appl. Phys. Lett. 99191501

[14] Blondel C, Chaibi W, Delsart C, Drag C, Goldfarb F and Kröger S 2005 Eur. Phys. J. D 33335

[15] Kimura K, Langford S C and Dickinson J T 2007 J. Appl. Phys. 102114904

[16] Serna R, de Sande J C G, Ballesteros J M and Afonso C N 1998 J. Appl. Phys. 844509

[17] Suarez-Garcia A, Gonzalo J and Afonso C N 2003 Appl. Phys. A 77779

[18] Baraldi G, Perea A and Afonso C N 2011 Appl. Phys. A 10575

[19] Resta V, Gonzalo J, Afonso C N, Piscopiello E and Garcia Lopez J 2011 J. Appl. Phys. 109094302

[20] Pokorný P, Mišina M, Bulî́r J, Lančok J, Fitl P, Musil J and Novotný M 2011 Plasma Process. Polym. 8459

[21] Brandenburg J, Neu V, Wendrock H, Holzapfel B, Krebs H U and Fähler S 2004 Appl. Phys. A 791005

[22] Amoruso S, Berardi V, Bruzzese R, Capobianco R, Velotta R and Armenante M 1996 Appl. Phys. A 62533

[23] Singh R K and Narayan J 1990 Phys. Rev. B 418843 